\section{INCORPORATION OF NEW DRUGS INTO THE UNIFIED HEALTH SYSTEM (SUS): EXISTING GAPS AND EMERGING NEEDS}

Gabrielle Kéfrem Alves Gomes

Cristina Sanches ${ }^{2}$

Mariana Linhares Pereira ${ }^{2}$

André Oliveira Baldoni ${ }^{2}$
The scientific and technological development and the expansion of the industrial complex in the health area do not necessarily bring more effective or financially more attractive technologies. The uncritical incorporation of new technologies can pose serious risks to the population, as well as compromise the sustainability of the health system. A health technology can be a medicine or equipment; a clinical or surgical procedure; or an organizational model of health care, for example. The incorporation of technologies in the Unified Health System (SUS) is a theme that mobilizes many interests in society, and decision-making on this issue must be transparent and systematized.

The Health Technology Assessment (ATS) is a form of research that assesses the use and consequences of technologies in the short and long term. It is an ongoing interdisciplinary process that connects three important areas: research, policy and management. The ATS studies aim to answer important questions as to whether the technology evaluated is effective and safe, whether its incorporation is economically attractive, or whether there are specific logistical, ethical and legal requirements for its incorporation into the health system. That is, its primary purpose is to guide decision-making 1

Although the implementation of ATS is a mandatory strategy in the federal sphere of the Unified Health System (SUS), the current guidelines are only recommendatory for the municipal sphere. Thus, the development of ATS strategies at the municipal level should occur according to local reality. 1 In this context, it is important to emphasize that improper incorporation of drugs can compromise the health priorities of the population and favor the costing of irrational treatments and that contradict the principles of equity in health and access to comprehensive and continuous therapeutic care ${ }^{2}$

In the case of health technologies, such as medicines, the use of information on the costs and benefits of health interventions can assist in setting priorities for resource allocation. ${ }^{2}$ And for this, it is necessary that the precepts of selection, programming, acquisition, storage, distribution and correct use of these inputs be rigorously followed, in order to guarantee continuous access to the drug treatment. However, a Pharmacy and Therapeutics Commission (CFT), which is one of the strategies used to promote and monitor the rational use of medicines, is needed to manage the use of tools in decision-making. ${ }^{3}$ In developed countries, when there is a need for the incorporation of new technologies, these commissions have already shown that they are fundamental, from the economic, social, and sanitary point of view. ${ }^{4}$ In Brazil, the performance of the CFTs is encouraged by the National Medicines Policy (PNM). ${ }^{5}$ However, Brazilian studies point to weaknesses in the performance of CFTs, which reflect in the selection of drugs that violate the concepts of essential and compromise the planning and execution of Pharmaceutical Services. It is also worth mentioning that CFTs should act in the definition of clinical guidelines as well as propose strategies for the monitoring and evaluation of new drugs incorporated into the health system. 4,6,7,8,9

Regarding Pharmaceutical Services, in Brazil, the judicialization of medicines influences the process of incorporation of medicines to be made available by the SUS, and this may interfere in a negative way in the execution of public health policies, considering that the compliance with certain legal actions for the supply of medicines, causes high and unscheduled expenses that jeopardize collective Pharmaceutical Services. ${ }^{2,10}$ On the other hand, the updating of protocols and therapeutic practices, sometimes under pressure from judicial processes, results in beneficial effects in order to accompany the development of health technologies. Faced with these counterpoints, it is necessary that public management work not only in order to meet judicial demands, but in conscientious selection of health technologies based on plausible scientific evidence and free from conflicts of interest. ${ }^{8,9}$

A succession of studies carried out within the management of a Brazilian municipality that incorporated linagliptin among the antidiabetics of the basic component of Pharmaceutical Services identified that:

a) the incorporation was preceded by high judicial demand in the municipality;

b) this pharmacotherapeutic alternative is considered too costly when compared to other options available in the SUS;

c) out of 108 patients indicated for linagliptin use, 18 (16.7\%) took the drug only one month for treatment;

d) 75 patients (69.4\%) did not have access to the drug continuously for at least three months;
1 Mestre em Ciências Farmacêuticas pela Universidade Federal de São João Del-Rei (UFSJ).

2 Professor Adjunto do curso de Farmácia e da Pós-graduação em Ciências Farmacêuticas da Universidade Federal de São João del- Rei (UFSJ).

Received: 10/01/2018 Accepted: 07/03/2018

How to cite this article: Gomes GKA, Sanches C, Pereira $\mathrm{ML}$ e Baldoni AO. IIncorporation of new drugs into the Unified Health System (SUS): existing gaps and emerging needs Rev. Bras. Farm. Hosp. Serv. Saúde, 9(2): 1-2, 2018

Doi: 10.30968/rbfhss.2018.092.009

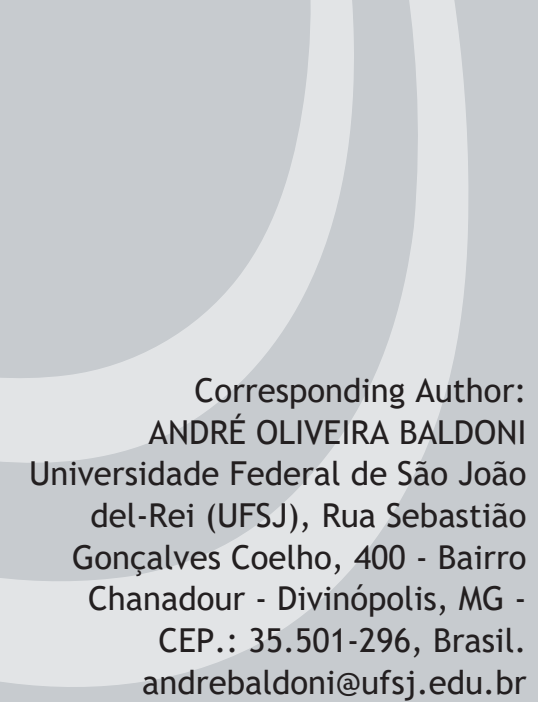


e) rhe effectiveness of the drug was lower than those presented by the clinical trials;

f) linagliptin accounted for $75.0 \%$ of total drug costs for DM2 control in the study population.

Besides these data observed in the real world, it was verified in the literature that:

a) The gliptine effectiveness profile was similar or inferior to traditional oral antidiabetics (sulfonylureas and metformin); 10

b) Sitagliptin associated with metformin is the most cost-effective option (in this analysis, alogliptin was not considered); ${ }^{11}$

c) The vast majority of clinical trials with linagliptin available in the literature (93.8\%) have reported funding from the pharmaceutical industry ${ }^{12}$;

d) Linagliptin is not present in the National Drug List (RENAME), in addition, there is a statement from the National Commission for the Incorporation of Technologies in SUS (CONITEC) about this drug, which highlights the arsenal of pharmacotherapeutic options for the treatment of DM2 already available in SUS and emphasizes the importance of non-pharmacological measures for the control of this disease. ${ }^{13,14}$

In view of these data from a "municipal case" and the precepts presented, it is essential to reduce the gap between the incorporation of new technologies and the technical-scientific analysis before and after the selection of a drug that will compose the list of medicines essential. Among the needs of this incorporation process, it should be noted that:

a) the real need of the population, considering the nosological profile;

b) other existing therapeutic options;

c) the critical analysis of existing scientific evidence;

d) the budgetary capacity to incorporate and maintain continued access to the drug;

e) the management's ability to measure the clinical and budgetary impact after the merger;

f) the coverage that the treatment will cover (or the supply of the technology from referral protocols). ${ }^{1}$

Finally, it is important that local managers assess the need for incorporation of new technologies within the scope of SUS based on technical precepts and the premise that the incorporation does not compromise the integrality and continuity of access to medicines, especially chronic health conditions.

\section{FINANCIAL SUPPORT}

This study was financed in part by the Coordenação de Aperfeiçoamento de Pessoal de Nível Superior - Brasil (CAPES) - Finance Code 001

\section{CONFLICT OF INTERESTS}

The author(s) declare(s) that there isno conflict of interest.

\section{AUTHORS' CONTRIBUTIONS}

GKAG, MLP, CS and AOB contributed with the conception and the design of the study; GKAG: performed the data collection and analysis;
GKAG, MLP, CS and AOB: participated in the critical analysis of the results and writing the first version of the manuscript. All authors contributed to the revision of the manuscript, read and approved the submitted version and are responsible for all aspects of the work in ensuring the accuracy and completeness of any part of the work.

\section{ACKNOWLEDGMENTS}

The authors thank the Federal University of São João del-Rei (UFSJ) Centro-Oeste Dona Lindu Campus (CCO).

\section{REFERENCES}

1. Ministério da Saúde. Entendendo a Incorporação de Tecnologias no SUS, Como se Envolver. Brasília, 36 p, 2016.

2. Nunes, R. P. A judicialização de medicamentos no sistema único de saúde. Revista de Atenção Primária a Saúde, 2016, 19(3):505-506.

3. Brasil. MINISTÉRIO DA SAÚDE. Departamento de Atenção Básica, 2010. Disponível em: < http://dab.saude.gov.br/>. Acesso em: 01 abril. 2018

4. Primo, L., P.; et al. Atuação da comissão de farmácia e terapêutica em um hospital de ensino. Medicina (Ribeirão Preto), 2015, 48(1): 27-32.

5. Brasil. Ministério da Saúde. Secretaria de Políticas de Saúde. Departamento de Atenção Básica. Política Nacional de Medicamentos. Brasília: Ministério da Saúde. 2001

6. Magarinos-Torres, R.; Oliveira, M. A.; Osório-De-Castro, C. G. S. Medicamentos essenciais e processo de seleção em práticas de gestão da Assistência Farmacêutica em estados e municípios brasileiros. Ciência e Saúde Coletiva, 2014:3849-3868.

7. Lima-Dellamora, E. C; et al. An Analytical Framework for Assessing Drug and Therapeutics Committee Structure and Work Processes in Tertiary Brazilian Hospitals. Basic \& Clinical Pharmacology \& Toxicology, 2014, 115: 268-276

8. Machado, M. A. A.; et al. Judicialização do acesso a medicamentos no Estado de Minas Gerais, Brasil. Revista de Saúde Pública, 2011, 45(3): 590-598.

9. Costa, M. R. Farmacoeconomia: uma antiga novidade. Rev. Brasileira de Farmácia Hospitalar e Serviços de Saúde, 2014, 5(4): 4-5.

10. Nogueira, T. A. S.; et al. Perfil de segurança e efetividade dos Inibidores da dipeptidil peptidase-4. Rev. Brasileira de Farmácia Hospitalar e Serviços de Saúde, 2014, 5(4): 6-12.

11. Cazarim, M. S.; et al. Cost-effectiveness analysis of different dipeptidyl-peptidase 4 inhibitor drugs for treatment of type 2 diabetes mellitus. Diabetes \& Metabolic Syndrome: Clinical Research \& Reviews, 2017, 11: S859-S865.

12. Gomes, G. K. A.; et al. Linagliptin safety profile: A systematic review. Primary Care Diabetes, 2018 (no prelo).

13. Comissão Nacional de Incorporação de Tecnologias no SUSCONITEC. Linagliptina para o tratamento do diabetes tipo 2. Ficha técnica sobre medicamento, 2p, 2016.

14. GOMES, G. K. A. Uso de linagliptina em pacientes atendidos pelo Sistema Único de Saúde (SUS). (Dissertação em Ciências Farmacêuticas) Universidade Federal de São João del Rei-CCO. Divinópolis, p. 95.2018 